\title{
THE RACIAL DERIVATION OF THE OSSETES
}

\section{BY KARL S. KENNARD}

Of the many tribes of barbarians which, from the fall of the Roman Empire, have left their mark of war or speech on the western portion of Europe, a few have been preserved in some form or other until the present time and have left the legacy of their manners or features to an admiring posterity. The Franks have contributed to the forming of one of the greatest of modern nations by the strength of their arms and have transmitted for its guidance the wise laws of eleven centuries ago. The Gothic love of adventure still survives in the spirit of their descendants. The Belgæ named the country of Belgium, while from the Teutonic Suevi modern orthography has fashioned the duchy of Swabia. In the combats, migrations, and changes of speech it is not unlikely that most of the tribes which contributed in one or another way to the changing of the chart as well as of the caste of Europe should have become to all purposes lost; so that, save in a few cases, the name alone survives as that of a people who once lived and fought for mastery of land and kind at and after the opening of the Christian era. It is therefore a matter of interest to inquire, of a tribe of people which occupied a more or less conspicuous place in the history of centuries past, whether or not there remains any trace in the physical characteristics of the people of to-day to form some idea of the racial stock to which they belonged, and whether their descendants or representatives, should any now exist, have departed in ethnical characteristics from the parent type. To determine this it is obviously necessary to gain some information of the original stock.

Anthropological investigations have developed the fact that the head form, color of hair and eyes, and stature are permanent and persistent racial features. Application of these tests to ancient and living mankind has demonstrated, especially in Europe, three physical types of race, namely, Mediterranean, Alpine, and Nordic. Should 
sufficient remains of an ancient people upon which to apply these tests be obtainable, problems of racial affinities between prehistoric and modern individuals are comparatively easy of solution. But when the expression of bygone people are found only in existing populations, the results are more difficult to obtain. However, with fairly accurate geographical localities furnished us, no longer misled by the idea that identity of speech means identity of race, and with the fundamental physical types of Europe defined, we are in a position to see what modern science and ancient geography combined might offer in an attempt to trace the affinity of some modern with some ancient people.

There is no more fertile field in which to attempt such an inquiry than that afforded by the Caucasian mountains. The Caucasus, on account of its geographical position, has been the meeting place of many nations. Occupying the waist of the isthmus between the Caspian and the Black seas, its girdle of high mountains has ever formed an insuperable barrier to migration; it offered no field for conquest; the invader always passed it by, and such inhabitants as it had were forced to take refuge in its fastnesses either by overwhelning attacks or through economic factors. From the south over Persia and Arabia, from the north by way of the Volga and the Don - from everywhere have types and kinds of people drifted to the foot of this barrier. But the inhabitants of this region were not affected by these - unmolested in their mountain home, they were able to retain the physical characteristics which they brought with them.

Of the tribal divisions of the Caucasus there are ten of importance. Of the dialects there are sixty-eight, each denoting, according to former opinion, a separate race of men. It was the polylinguistic factor that gave rise to such theories. But when this apparent diversity of population is examined by modern anthropology, a different opinion is reached. First, the form of the head shows an index ranging from 86 in the Lesghians to. 83 in the Tchetschens, indicating marked brachycephaly. Again, all the Caucasians are dark, with chestnut hair and brown or black eyes as a rule. In stature they range from 5 feet $4 \frac{1}{2}$ inches to 5 feet 6 inches. How is it that such uniformity of physical type here prevails? The belief is that that type of people possessing the greatest aptitude and 
adaptiveness to mountain environment has selected these higher altitudes for its habitat, while others have either settled at the base of the mountains or have passed on through the only gateway to the north, the Pass of Dariel. For those who selected the mountains as their home, isolation, both general and contiguous, has been complete. They have not blended with each other nor with other people, so that their primary characteristics, and especially the broad-headedness which these mountaineers possess, were theirs in the beginning, having been brought from their original center of distribution. In other words, they possess in all its purity that physical type, known as the Alpine type, which is found throughout the central part of Europe to the Pyrenees. As before stated, the form of the head being the most persistent of the physical criteria of race, and all the more so when favored by isolation, it is not to be believed that this feature among the Caucasian tribes is an acquired one. It is a racial factor pure and simple.

From what direction are we to believe that the Alpine type entered Europe? Surely not from the north, for that region furnishes an entirely different racial type, namely, the Nordic. The path of the Alpine race is clear. It extended from the Pamir, through the north and east of Persia, across Asia Minor, and into the mountains of Central Europe, to Spain, while here in the Caucasus is the connecting link.

From the general uniformity of head-type that has been shown to occur in this locality, there are two exceptions. One is found in the tribe of the Ossete, lying on both sides of the mountains, around the Pass of Dariel; the other, among the Abkhasians, lying over against the Black sea. The latter are a branch of the Circassians. The custom of cranial deformity is prevalent among them, rendering cranial measurement very uncertain. Yet even with this they possess an index of $8 \mathbf{I}$, and their longheadedness is more apparent than real. Thus of all the population of Caucasia the Ossetes only present a deviation from the prevailing type. They form an exception to the rule. This is a most important fact.

Since the publication, in 1885 , of the results of Chantre's investigations on the inhabitants of the Caucasus, the Ossete have been regarded as a people immigrant into this region. And even be- 
fore this time historians found much similarity between their manners and customs and those of the Goths, Germans, and other Teutonic tribes. It has further been believed that these people form the remnant of the tribe of the Alani, who occupied the region to the northward some time before the fall of Rome. However this may be, their position upon the only pathway through this territory makes the theory that they are not indigenous to the country at least tenable. The main question is : From what direction did they come? We will see that they cannot be included among the Alpine people of this region. The direction of their emigration was either from the north or from the south. They are newcomers of comparatively recent date - certainly within the historic period. And as this region does not afford any peculiar economic advantages, some force other than the mere desire of migration brought them here. It is generally believed that these people migrated from the south - from the Iranian plateau and Arabia. Let us see if the facts warrant the conclusion.

In the region of Iran there are two racial types, both present in the modern population, both to be found in the remains of the far more ancient one. No change in the physical characteristics of these people has occurred since the earliest times. One of these types, the Alpine, need not concern us here. The other, the Mediterranean, is the one from which the Ossetes, if they came from this direction, are bound to be derived. The Persians, the Kurds, the Afghans, and the Hindus all belong to this race. "These people are all long-headed and dark brunettes, inclined to slenderness of habit, although varying in stature according to circumstances." We recognize in them also the southern Italians, the Spaniards, and the Portuguese-dolicocephalic (cephalic index between 75 and 80 ), black or dark-brown eyes, stature varying between 5 feet I inch and 5 feet 6 inches. These are the physical characteristics of the Mediterranean race.

Now, what does anthropology show in regard to the Ossetes? As is to be expected, their cephalic index ranges from 79 to $8 \mathrm{r}$. One of the features which distinguishes them from the other inhabitants of the Caucasus is long-headedness. It is true that they are at the top of the long-headed list, but of this more anon. The nose 
is long, straight, and thin at the end, certainly a contrast to the broad, flat end and spreading alænasi of the Kurds and the Suzian. In stature they are tall. Measurements which I personally made upon seven Ossetes at the Immigration Station, Ellis Island, New York, in the winter of 1904 , give the following results: Two presented a height of 5 feet $7 \frac{1}{4}$ inches, one each of 5 feet $6 \mathrm{r} / 4$ inches, 5 feet $63 / 4$ inches, 5 feet 6 inches, 5 feet $71 / 8$ inches, and 5 feet 7 inclies.

Having at the station, at the same time, many individuals of the Mediterranean race, the contrast was all the more striking, even to simple observation. But not upon this small number of observations only do we form an opinion. It is a fact, proven by numerous authorities, that the Ossetes are a tall people, and stature, as we shall see, is a persistent feature of a certain racial derivation. Lastly, the most peculiar fact of all is, that more than 30 percent of them are blonds. Such a proportion occurs nowhere else in or near the Caucasian mountains; nor does it occur among any other people supposed to be derived from a Mediterranean stock. Of the seven individuals before mentioned, five had blue eyes and lightish hair, the darkest of these five having light-brown hair. Of the others, one had gray eyes with dark-brown hair, and the last had hazel eyes and black hair. As stated, we know all the Caucasians to be dark brunettes, this form of pigmentation prevailing everywhere throughout this region.

But here are some strange facts relating to the Ossetes, especially if they are immigrants from the direction of Iran. They have either departed from their original type if they came from the south (and that in a comparatively short time), or else they never came from that region at all. If they are an offshoot of the Mediterranean race, they must have brought with them the physical characteristics of that racial type. Nor did they branch off from this parent stock with stature and blondness as their heritage. The Mediterranean traits we have detailed above. If the Ossetes once possessed these features, how did they lose them ? Not by blending with the original inhabitants of the mountains, for among them are no blue-eyed or light-haired people. But, granting such to be present, the mountain isolation prevents intermixture in this region. 
Racial individuality is here complete. Nor does the altitude suffice to explain the phenomenon of these blond traits, for if this factor produced a change of 30 percent in the Ossetes, why did it not have a similar effect on other mountain tribes in this locality? Again, there is their stature. This altitude could not have effected a change from a Mediterranean stature to one of 5 feet 6 or 8 inches ; fertile soils, such as rich plains afford, and a hospitable environment are required for that. These are not found here. Mountain life does not increase stature, it rather tends to shorten it; and if the Ossetes are a tall people in their present habitat, it is safe to assert that they were always so. If we have here any result of the influence of altitude on stature, it would seem to be that of retrogression - a change from tall to medium sized.

Nor can we account for the blond trait among the Ossetes either by racial intermixture, as we have seen, or through the effect of altitude, although the latter favors blondness. The effect of altitude on pigmentation does not here correlate with stature, for mountains do not increase stature and produce blondness at the same time. If such does occur, however, another factor - that of race - is at work, but that is absent here. Nor does social selection explain the situation from the Mediterranean point of view, for the inbreeding of these primary traits would serve only to accentuate them, and shorter stature and darker. hair and eyes would result. Thus, eliminating the factors of environment and racial intermixture or selection of any kind, the height and the blond tendency of these people seem to us to be simply a matter of race.

It would therefore appear that one cannot look to the direction of Iran or Arabia as the place of origin of the Ossetes. They do not possess the characteristics of the peoples of this region; and in the Caucasia no blond or tall people have offered the opportunity of assimilation. As we have endeavored to show that the Ossetes do not possess the features of the Mediterranean type, we must see if the north can aid us in our search.

To the south of the mountains we have observed that there have prevailed since ancient times two racial types. To the north we find that to-day there are two - the Alpine (a recent intrusion into Europe from the southeast), represented by the Slavic people, and 
the Mongol tribes about the Black and Caspian seas. It is of the country outside of the mountains that we speak, for in the highlands themselves the Alpine race has long been established.

The other racial type found in the north is the Nordic, a highly specialized type represented by the tall, blond, long-headed Germans, Scandinavians, and Lithuanians of the present time. This type is likewise a very old one in southern Russia, and has left its impress on the land in which it lived and on its inhabitants. Possessing characteristics distinctive enough to qualify it, it is not needful to our purpose to discuss its more primitive origin. It constitutes a well-recognized and separate ethnic type of high antiquity, and is to be treated as one of the fundamental races of mankind.

Long before the advent of the Alpine race into Europe the Nordic race had occupied the territory north of the central highlands of the continent in the pristine manner of early man. Gradually responding to the laws of social and other forms of evolution, its representatives passed through successive stages of culture, until finally we find them separated into tribes, clans, and families, possessing the manners and customs characteristic of their social and intellectual status. Let it be remembered that unless we go back to a period antedating even the specialization of the Nordic race, namely, to the early Stone age, we have no evidence of any people other than this Nordic type occupying the northern portion of Europe and extending southward to the Alps. This evidence is exemplified by the population of to-day. The Finns are the representatives of these ancient people driven asunder by the incoming Alpine invasion from southeastern Europe. Pushed to the north and to the south of Russia, their descendants now occupy the corners and edges of the region where once they were supreme.

As tribal formation is a social characteristic as well as a natural safeguard of even the most primitive of human beings, we would naturally expect to find such a state of affairs among these people. In truth, historians tell us of and locate accurately for us a tribe called the Alani, which about two hundred years before the Christian era occupied the territory north of the Caucasus mountains and extended northward between the Volga and the Don. They have been described to us as a bold, warlike people, rejecting slavery, having 
an elective monarchy, a religion advanced beyond the nature worship of savages, refusing to practise the custom of self-mutilation, and following their conquests by colonization. Of white complexion and yellowish hair, can it be doubted that here are described a tribe of the Nordic type? With institutions and an individualization thus far advanced before any racial migrations, before any chance of racial displacement or intermixture, when Rome alone represented the civilization of the world, we can not doubt that the Alani are of a race of high antiquity. And from whom else could these people be derived if not from that racial type so prevalent at that early period in this part of Europe? Archeology as well as anthropology has shown us that these people were the Finns.

Engaging the Roman arms at various periods in their history, the Alani retained their power and political independence until i 76 A. D., when they suffered severely from an invasion of the Huns, by whom the tribe was divided, the majority accepting the favor rather than the sword of their conquerors, whose army they accompanied into western Europe. Separating from the Huns in Pannonia, they associated themselves ${ }^{1}$ with various Teutonic tribes. They established settlements in Gaul and Spain, especially around the cities of Orleans and Valencia, and in Lusitania and Bœotia, where after some years they lost their identity by becorning merged with the conquering Visigoths.

That portion of the Alani who escaped captivity remained in their former position, maintaining sorne political independence, witnessing the Slavic invasions of the ninth century, the Mongol and Tartar raids in $122 \mathrm{I}$, and finally subjected by the Mongols in 1227, they disappear from history. Yet on the outskirts of the country which they once held and in the locality where their national unity was destroyed, we find a population presenting the physical characteristics of an ancient northern type. Dare we assert that the Ossetes are the remnants of these Alani? The idea is not new. We have tried to approach it only from the anthropological side. It has been conceded that the Ossetes are not indigenous to the Caucasia ; the position which they occupy seems to indicate that they

In the absence of any stated reason for this, may we offer "consciousness of kind" as one?

AM. ANTH., N. S., 9-19. 
are en route as it were. And we believe that we have proven - if physical characteristics count for anything - that they are not of southern derivation. At least it is our theory that the Alani, being pushed from their home land by Hun, Mongol, and Tartar, decimated and dispersed by successive invasions, have retreated into the mountains and occupy, as a last stand against the Asian hordes, the only position they could obtain - the country around the Pass of Dariel. For the mountain fastnesses had long been occupied by the broad-headed Alpine type. And as the Alani at 200 years B. C. were well seated in southeastern Russia, to what people but the Finns can we look as their progenitors? Archeology and anthropology have proved that the Finns occupied all of Russia. They conform to the classical Nordic type, and if the Ossetes present distinctly two of its features and show evidence of having once possessed the third, what other inference can be drawn? We have shown the Ossetes to be tall, and, in dismissing the subject of stature, we quote from one of the leading authorities that, " never has a physical trait shown so surprising a persistency as in the height of the Teutonic people."

Another question that must be squarely met is this: Is it possible that, thirty percent of the Ossetes being blond, seventy percent have deviated from the original type? Would it not seem more probable that the smaller proportion represented the change in pigmentation? If all the Ossetes entering this region were brunette, in what manner could the thirty percent deviate from the original? We are unable to determine how, and have gone to some length to prove it. Not racial intermixture, for there are no light populations here from which to draw. Not social selection, for brunette traits would become only the deeper. Not environment, for the law governing stature is against that as well as the absence of any marked degree of blondness in the other mountaineers.

On the other hand, if all were originally blonds, how would it be possible for seventy percent to deviate from and thirty percent remain true to the original type? Nevertheless, we believe that this has happened. Bearing in mind the facts that the Ossetes occupy the only passage across the mountains, thus having egress 
to the country lying on each side of them, that the inhabitants of the lower lands can thus pass to and fro through their territory, and that racial intermixture in later times is much easier owing to various economic factors than before the nations were so intimate one with another, is there any reason to doubt that the Ossetes, open to these outside influences which the other tribes on account of their isolation were denied, have not been thereby affected? Racial intermixture with outside populations is possible. Jews are abundant here, and among the Ossetes many Jewish features occur. Such admixture is certainly destructive to blondness. Perhaps Mongol and Armenian influences, as well as those of the Russian Slavs and Tartars in the north, have lessened the light characteristics. All these peoples, it should be remembered, are dark; as pigmentation is far more susceptible of change than head-form, we can conceive of this change in blondness occurring without destroying other characteristics.

It will be noticed in the preceding discussion that we have made but slight reference to the most reliable of all physical criteriahead-form. In distinguishing the Mediterranean from the Nordic race, it affords us no assistance, as the index is the same in both cases. We know that the Ossetes are longer-headed than the other Caucasians, and we believe long-headedness, in conjunction with the other two traits, to be their fundamental feature ; yet we found them well toward the top of the dolichocephalic list. May not the attenuation of their long-headedness be due to the same cause as the gradual obliteration of their blond traits, since the outside people - Jews, Armenians, Tartars, and Slavs - are all round-headed? The Ossetes are "in transit," geographically as well as physically, from a higher to a more degenerate type. If they have degenerated from the physique or morale of former times, as they seem to have done, cannot the vicissitudes of theil- history help us to appreciate that fact? For although they appear to be a people whose physical characteristics are in process of attenuation, whose blondness is being washed out, whose head is becoming squared and height depressed, yet they retain enough of the noble features of race to attest their origin.

We have tried to approach every side of the question, even at the risk of becoming tedious. In conclusion, as a general summary, let us state the following propositions : 
The Ossetes, as held by historians, are the remnant of the tribe of the Alani. They were primarily a long-headed, tall, blond people, which characteristics they retain in some measure at the present time. Driven to the Caucasian mountains by barbaric invasions, they occupy the only available locality - the Dariel pass - as the more remote mountain regions were long since occupied by Alpine people. By racial intermixture with later arrivals, the Ossetes are gradually losing the primary elements of blondness and long-headedness.

The Alani were a tribal division of the Finns who occupied the southern part of Russia north of the Caucasian mountains. Their customs and institutions show them to be of ancient origin, to have been in a state of political independence and with distinct physical characteristics before the appearance of any other racial type in these regions.

Lastly, the Finns are a branch of the great Nordic race occupying the whole of Russia and northwestern Europe from prehistoric times. Their remains are found on archeological sites and their descendants are represented by the Lithuanians, Esths, Tchuds, and the Great and White Russians of the present time.

U. S. ImMigration BUREAU, Ellis ISLAND, NeW York. 